\title{
Hypoxanthine Concentration in Plasma during the First Two Hours after Birth in Normal and Asphyxiated Infants
}

\author{
LARS-ERIC BRATTEBY ${ }^{(32)}$ AND STEN SWANSTRÖM \\ Perinatal Research Unit of the Department of Pediatrics and the Unit of Pediatric Physiology of the Department of \\ Clinical Physiology, University Hospital, Uppsala, Sweden
}

\begin{abstract}
Summary
The measurement of arterial plasma concentration of hypoxanthine in $\mathbf{1 6}$ healthy newborn infants showed a prominent increase after birth compared with the umbilical cord levels. Peak values were found 10-20 min after birth with a maximal value of 11.9 $\mu$ mole/liter in the normal newborns. In five asphyxiated infants the postnatal pattern of hypoxanthine was the same as for normal infants but the increase was even more prominent. A mean peak value of $33.7 \mu \mathrm{mole} / \mathrm{liter}$ was noted in the asphyxiated infants. Our results indicate that the hypoxanthine concentration is influenced not only by the degree of hypoxia, but also by the peripheral circulation and the time interval between the hypoxic event and the blood sampling. It is concluded that hypoxanthine assay may be of clinical value for the detection of past hypoxia as a semiquantitative test.
\end{abstract}

\section{Speculation}

It is possible to differentiate a group of asphyxiated infants from normal infants by measurements of plasma hypoxanthine concentration. A new biochemical measure of perinatal hypoxia thus appears available. Knowledge about the change in hypoxanthine concentration is however of much greater value than that of a single plasma sample which may be misleading.

The theoretical connection between lack of oxygen, reduced cellular energy contents, and the catabolism of energy-rich phosphates (e.g., ATP, ADP) has been known for a long time. Until recently, however, the estimation of purine metabolites has not been used in clinical practice as a measure of hypoxia. With a micromethod for determination of the hypoxanthine concentration in plasma, Saugstad (18) found this metabolite to be a sensitive sign of hypoxia in experimental animals $(20,21,22,23$, 24) and his preliminary clinical results also indicated a constant and slow decrease of this concentration after a period of fetal hypoxia. He therefore proposed that hypoxanthine measurements could be used for a retrograde estimation of past episodes of hypoxia in the newborn infant (19). In the umbilical cord plasma a hypoxanthine level of $11 \mu \mathrm{mole} /$ liter was found to discriminate newborn infants with normal deliveries from infants with signs of intrauterine asphyxia (19). Lipp et al. (11), however, found that the hypoxanthine concentration in umbilical cord plasma from asphyxiated newborn infants overlapped in a rather broad range the values obtained from normal infants. This was true for both arterial and venous cord blood.

In view of this discrepancy, the present study was undertaken in order to investigate the change in postnatal arterial hypoxanthine concentration in a number of normal and asphyxiated newborn infants who had been carefully monitored during delivery and in the early postnatal period. In some of these infants, the hypoxanthine concentration was also measured in venous cord blood and in the immediate neonatal period in blood samples obtained from the umbilical vein.

\section{MATERIALS AND METHODS}

A control group and five asphyxiated newborn infants were studied. All infants were born at the Department of Obstetrics and Gynecology of the University Hospital in Uppsala.

\section{CONTROL GROUP}

Sixteen full-term newborn infants with a normal 1-min Apgar score $\geq 8$ and an uneventful neonatal adaptation were selected from a group of subjects investigated as part of another study. The mean birth weight was $3312 \pm 423 \mathrm{~g}$ and the gestational age 276 \pm 8 days. All parturients had an uneventful pregnancy with no intercurrent disease. All were vaginal deliveries after a spontaneous onset of labor. In the newborn infants, determinations of blood gases, acid-base balance, and lactate were made on arterial blood obtained during the first $2 \mathrm{~h}$ of life. All results were in accordance with reference values for normal infants reported by other investigators $(1,2,4,7,10,15,16,27,28)$. Clinical observations during the early neonatal period and the first week of life were all normal.

\section{ASPHYXIATED INFANTS}

Case 1. The Apgar score was 2 at $1 \mathrm{~min}, 2$ at $5 \mathrm{~min}$, and 5 at 20 min of age. The birth weight was $3160 \mathrm{~g}$ and the gestational age $40 \mathrm{wk}$. Severe intrauterine and postnatal asphyxia occurred after a paracervical block with transfer of the local anesthetic drug (lidocaine) to the fetus. Immediately after the block, fetal bradycardia occurred, with a heart rate of $50-60$ beats per min as recorded cardiotochographically. Because of persistent bradycardia, Caesarean section was performed within $40 \mathrm{~min}$. Traces of lidocaine were found $23 \mathrm{~h}$ after birth in the blood, urine, and aspirates from the stomach. At the age of 9 months this infant showed delayed psychomotor development.

Case 2. The Apgar score was 1 at $1 \mathrm{~min}, 4$ at $5 \mathrm{~min}$, and 7 at 15 min of age. The birth weight was $3220 \mathrm{~g}$ and the gestational age $43 \mathrm{wk}$. This infant was born in the breech position. The fetal heart rate and fetal scalp $\mathrm{pH}$ were normal before birth. The asphyxic episode was believed to have occurred at the very end of expulsion, as is often seen during a breech delivery (8).

Case 3. The Apgar score was 4 at $1 \mathrm{~min}$ and 7 at $5 \mathrm{~min}$ of age. The birth weight was $2830 \mathrm{~g}$ and the gestational age $36 \mathrm{wk}$. The presentation was anomalous, with a prolapsed extremity. During the external and internal manipulation all signs of fetal heart activity disappeared. Fetal death was suspected, but signs of fetal heart activity reappeared and an emergency Caesarean section was performed.

Case 4. The Apgar score was 3 at $1 \mathrm{~min}, 6$ at $5 \mathrm{~min}$ and 9 at 10 min of age. The birth weight was $2830 \mathrm{~g}$, and the gestational age $43 \mathrm{wk}$. The amniotic fluid was meconium-stained when amni- 
otomy was performed $7 \mathrm{~h}$ prior to delivery. Vacuum extraction was done because of late decelerations, with a fetal heart rate of 80 beats per min. This infant showed marked signs of dysmaturity.

Case 5. The Apgar score was 9 at 1 and 5 min of age. The birth weight was $3170 \mathrm{~g}$ and the gestational age $38 \mathrm{wk}$. This was an incomplete breech presentation with a double footing position. The infant was included in the group of asphyxiated infants because of the clinical history and on biochemical grounds, although the Apgar score at $1 \mathrm{~min}$ was normal. The base deficit value was $16 \mathrm{mmole} / \mathrm{liter}$ and the blood lactate $10.5 \mathrm{mmole} / \mathrm{liter}$ at $10 \mathrm{~min}$ of age.

\section{CLINICAL PROCEDURE}

Infants in the control group were monitored during labor with continuous external and/or internal cardiotochographic recording and in some cases also intermittent scalp blood sampling. After birth a catheter (Argyle 5 Fr.) was introduced into an umbilical artery and the infant was placed in an intensive care incubator. During the first $2 \mathrm{~h}$ of life the infant was observed clinically, ECG and transthoracic impedance were continuously monitored and the arterial blood pressure was recorded intermittently. Arterial blood samples were obtained from the umbilical artery catheter $10,20,30,60,90$, and $120 \mathrm{~min}$ after birth. In some asphyxiated infants the sampling time varied because of resuscitative efforts or transportation. In eight infants of the control group and in two asphyxiated infants blood was also obtained from the umbilical cord vein. The vein was punctured after clamping of the cord, which was done $3 \mathrm{~min}$ after birth in the control group and immediately after birth in the asphyxiated infants. In some of the infants, blood was also obtained through a catheter in the umbilical vein simultaneously to the arterial blood sampling. In these cases the tip of the catheter was introduced only a few centimeters and was therefore probably situated in the vicinity of the portal sinus. Blood was drawn into heparinized syringes. Care was taken to put the samples on ice, and for the hypoxanthine assay to separate the plasma as soon as possible.

\section{METHODS}

Hypoxanthine was assayed by the micromethod for measuring oxypurines in plasma as described by Saugstad (18). All assays were performed with the equipment used by Saugstad in this laboratory. The change in oxygen tension after the addition of xanthine oxidase to the plasma sample was observed on a $\mathrm{PO}_{2}$ scale and recorded on paper (Varian Aerograph Model 20). The reaction was judged to be complete when the decline in oxygen tension was brought to a halt, which generally occurred within 45 sec. Twenty $\mu \mathrm{l}$ of Catalase (Boehringer, Mannheim; activity approximately $50,000 \mathrm{U} / \mathrm{mg}$ ) were added to the plasma to avoid peroxide formation. The error of a single hypoxanthine measurement in the present series, as estimated from 18 duplicate determinations in the range from $0-18.2 \mathrm{mmole} / \mathrm{liter}$, was $1.8 \mathrm{mmole} /$ liter, i.e., of the same order of magnitude as reported by Saugstad (19).

\section{RESULTS}

The principal findings in this study are the following: (1) an early postnatal increase in arterial plasma hypoxanthine concentration followed by a decrease in both normal and asphyxiated infants; (2) this early change was more pronounced in asphyxiated than in normal infants; and (3) the hypoxanthine concentration at different intervals after birth was higher in the former infants than in the latter.

In eight normal and two asphyxiated infants hypoxanthine determinations were made in plasma of blood obtained from the umbilical cord. The first postnatal arterial blood sample had a higher hypoxanthine concentration than the umbilical cord vein in all cases but one. In this case the concentration was only slightly lower, $1.4 \mathrm{mmole} /$ liter at $15 \mathrm{~min}$ of age. The change from the umbilical cord vein to postnatal peak arterial values ranged from

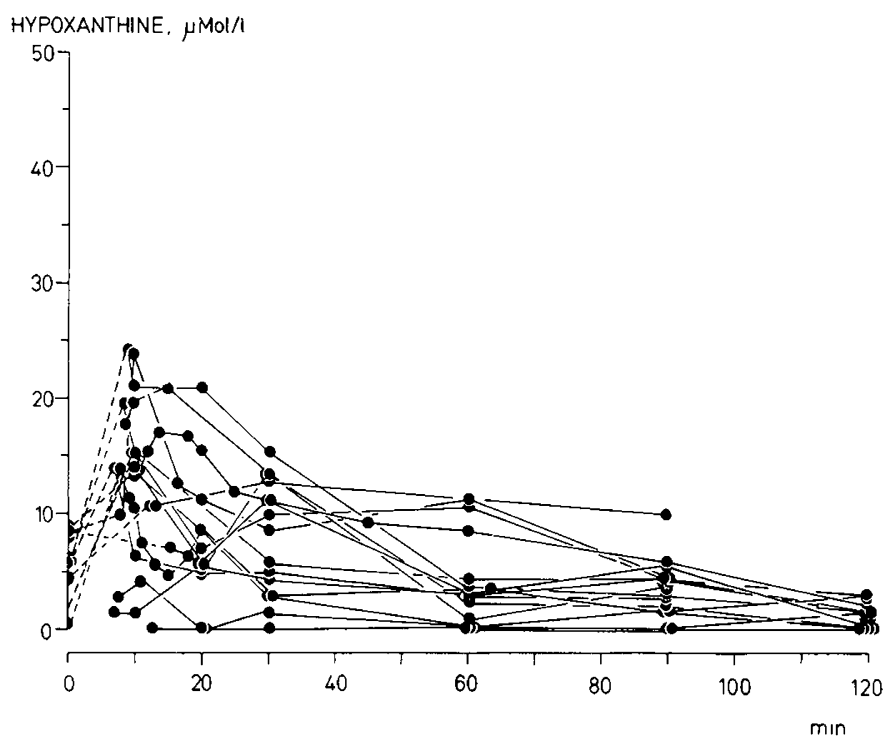

Fig. 1. Hypoxanthine concentration in arterial plasma (๑) in normal infants during the first $120 \mathrm{~min}$ after birth. Hypoxanthine concentration in the umbilical cord vein (O).

-1.4 to +18.9 , mean +9 mmole/liter, in normal infants. In the two asphyxiated infants this increase amounted to 16.8 and 18.9 mmole/liter, respectively.

The changes in hypoxanthine concentration in the normal infants are illustrated in Figure 1 and in the asphyxiated infants in Figure 2. The pattern of change was the same in both groups. As a rule the highest arterial values were found within the first 20 min after birth. In the control group, the peak arterial values during this period ranged from $0-23.8$, mean 11.9 mmole/liter. In the asphyxiated infants, the range of peak values was $18.8-48.3$, mean 33.7 mmole/liter.

The subsequent change showed individual variations, but the general trend was a rapid decrease from the peak values. The mean decrease from the peak concentration in the first $20 \mathrm{~min}$ after birth, to the value at $30 \mathrm{~min}$, was $5.7 \mathrm{mmole} /$ liter in the control group and $19.9 \mathrm{mmole} / \mathrm{liter}$ in the group of asphyxiated infants. From 30 min onwards, the change in hypoxanthine concentration was less pronounced and, again, a large individual variation in the concentration was observed particularly in the group of asphyxiated infants.

In two of the latter infants an infusion of 6 mmole of sodium bicarbonate was followed by an increase in the hypoxanthine concentration by 10 and 6 mmole/liter, respectively, as indicated in Figure 2.

The relationship between hypoxanthine values of 14 paired blood samples obtained simultaneously through an umbilical arterial and an umbilical venous catheter between 7 and $25 \mathrm{~min}$ after birth is described by the equation $\mathrm{Y}=3.0+0.72 \mathrm{X}$. The correlation coefficient was $0.66(P<0.01)$. In the range between 1 and $24 \mathrm{mmole} / \mathrm{liter}$ for the umbilical arterial blood samples the mean of the differences was $0.41 \pm 5.1 \mathrm{mmole} / \mathrm{liter}$. Using Student's paired $t$ test, no statistically significant difference between arterial and venous values $(t=0.23, P<0.1)$ was found.

\section{DISCUSSION}

In this study, very rapid changes in the hypoxanthine concentration after birth were noted, particularly in infants who, for clinical or biochemical reasons, were considered to be asphyxiated in the perinatal period (Fig. 1 and 2). The characteristic pattern of hypoxanthine changes both in the infants of the control group and in the asphyxiated infants was an early and pronounced increase from the umbilical cord concentration, followed by a decrease. The apparent discrepancy between this pattern of changes and the slow hypoxanthine decrease noted by Saugstad in his preliminary 


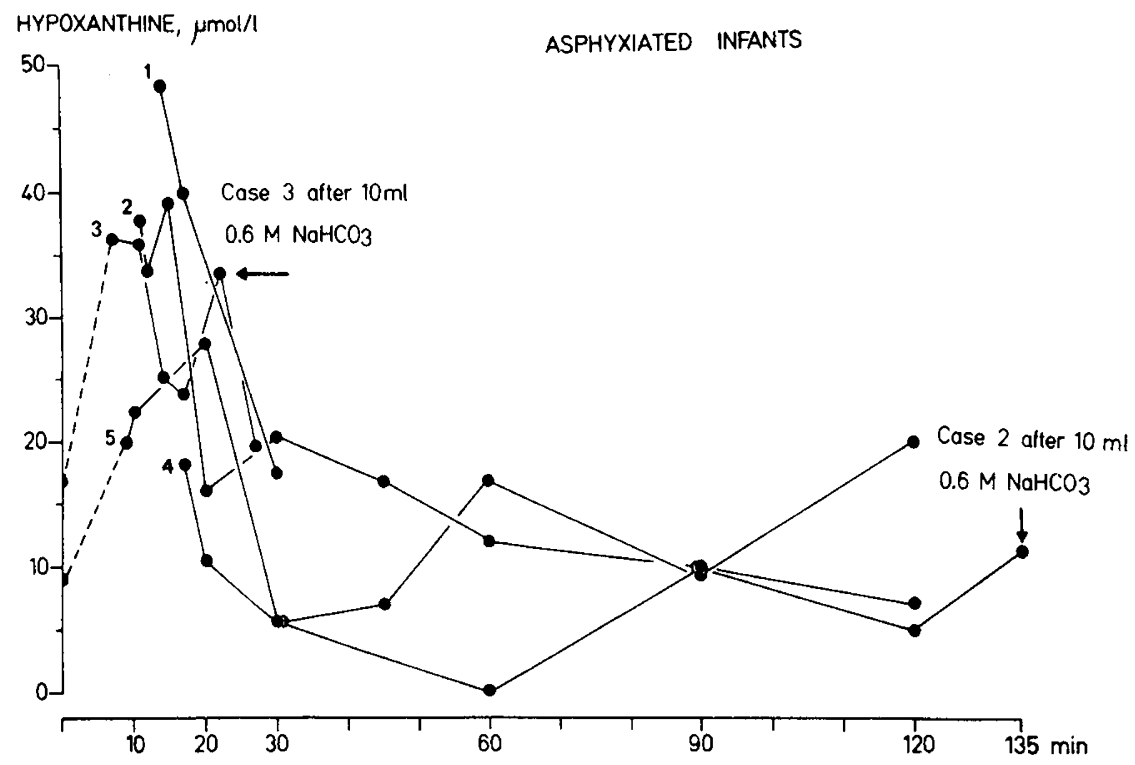

Fig. 2. Hypoxanthine concentration in arterial plasma ( $)$ in five asphyxiated infants during the first 120 min after birth. Hypoxanthine concentration in umbilical cord vein (O). Arrows indicate hypoxanthine concentration $5 \mathrm{~min}$ after buffering with $10 \mathrm{ml} 0.6 \mathrm{M} \mathrm{NaHCO}_{3}$. $\left(\mathrm{Cases}_{2}\right.$ and 3$)$.

study (19), and indicated in a study by Maaser et al. (12), is most likely only due to the fact that we were better able to observe a postnatal peak in hypoxanthine concentrations, owing to more detailed information from a larger number of samples.

A pattern of changes similar to that observed for hypoxanthine in this study, with an early postnatal increase followed by a decrease, is also known for base deficit and lactate $(2,28)$. The hypoxanthine concentrations, however, seemed to change more rapidly and more extensively than what is known for lactate or base deficit during the same time intervals after birth (26).

The increase in hypoxanthine concentration to peak values after birth could be due to a delayed influx of this purine metabolite from the hypoxic cell to the extracellular fluid and thence to the plasma. It might also be due to a delay in the perfusion of tissues subjected to hypoxia. As hypoxanthine is not electrically charged, its diffusion out of the hypoxic cell is probably not a rate-limiting factor for its appearance in blood plasma. On the other hand, a marked peripheral vasoconstriction is known to occur immediately after birth both in normal and in asphyxiated infants (5). With severe asphyxia both a reduced cardiac output and a redistribution of the blood supply to the brain and heart may leave less vital tissues with a decreased blood flow (25). Thus, hypoxanthine would be trapped in underperfused and hypoxic tissues. Only when the peripheral blood flow increases after birth (6) and asphyxia is relieved will a bolus of hypoxanthine be washed out and appear in central venous and arterial blood.

Buffering is known to improve peripheral blood perfusion (3) and, in the present study, an infusion of sodium bicarbonate was in fact followed by a pronounced increase in the hypoxanthine concentration. In agreement with this observation, Saugstad also noted an increase in the hypoxanthine concentration after reinfusion of blood in dogs previously made hypovolemic (22).

The problem of estimating the degree of past asphyxia by means of hypoxanthine assays in blood samples obtained from the umbilical cord at birth is illustrated in Figures 1 and 2. Infants with similar hypoxanthine concentrations in their cord blood showed very different concentrations after birth. This finding is in accordance with the report by Lipp et al. of overlapping hypoxanthine concentrations in cord blood from asphyxiated and normal infants (11). In view of the possibility that hypoxanthine may be trapped in different tissues for circulatory reasons, as discussed above, one must expect cord values of hypoxanthine to vary not only with the degree of and with the time interval from a hypoxic insult, but also with the circulatory state. This will explain why an infant with a minor hypoxic insult at birth may have higher hypoxan- thine concentrations in the umbilical cord blood than an infant with more extensive hypoxia and a secondary redistribution of the circulating blood. It should be mentioned that lactate concentrations were found to lack a significant correlation to the Apgar score, when determined in blood obtained from the umbilical cord in a study by Kaneoka et al. (9). In blood obtained 15-60 min after birth, however, these authors observed highly significant correlations between lactate levels and Apgar scores, in accordance with our study on lactate in normal and asphyxiated newborn infants (4).

It was proposed by Saugstad that estimation of the hypoxanthine concentration in plasma could be used as a sensitive and quantitative test of hypoxia (19). The present investigation confirms that fetal hypoxia can be traced postnatally from an elevated hypoxanthine concentration, as the asphyxiated infants had significantly higher hypoxanthine concentrations than normal infants after birth. Knowledge about the rapid changes of the hypoxanthine level and the appearance time of peak values is important. This is illustrated in Figure 1 and 2, where it is seen that two infants had similar hypoxanthine values $(5 \mathrm{mmole} / \mathrm{liter})$ at $30 \mathrm{~min}$ of age but the change in hypoxanthine concentration in the time interval 10-30 min after birth was quite different. A single value can therefore not be expected to give a strict quantitative estimation of past hypoxia. This limitation also applies, however, to all other known biochemical means of estimating past hypoxia (17). In our previous study on arterial lactate in normal and asphyxiated infants (4) it was noted that although lactate concentrations were strongly correlated to clinical signs of asphyxia for a long time after birth, the possibility of discriminating individual infants subjected to hypoxia by means of the lactate concentration was limited.

One would expect that hypoxanthine assay could be more useful as a quantitative measure of hypoxia under standardized experimental conditions, with possibilities of frequent sampling and/or knowledge of the exact time of occurrence of hypoxia, than in clinical practice. In clinical work, the number of samples must be limited. Nevertheless important qualitative information may be obtained from the hypoxanthine determinations. The possibility of measuring the total excretion of purine metabolites, e.g., in the urine, might be expected to better fulfill the theoretical requirements of a quantitative variable of hypoxia. In a recent investigation, however, only $58 \%$ of infants with perinatal complications had an increased oxypurine excretion $(13,14)$.

Our conclusion from this study, based on the fact that the asphyxiated infants had significantly higher hypoxanthine con- 
centrations in postnatal blood samples than the control group, is that the hypoxanthine test as described by Saugstad (19) may very well serve as a semiquantitative test of perinatal hypoxia. The results, however, also indicate that the hypoxanthine concentration is not only dependent on the duration and degree of hypoxia, but to a very large extent is also influenced by the time interval between the occurrence of hypoxia and blood sampling and by the peripheral blood flow during this period. The plasma concentration of hypoxanthine should also be influenced by changes in the plasma volume, extracellular volume and rate of hypoxanthine disappearance from the plasma. Furthermore, it is possible that in some cases, hypoxanthine of maternal origin may appear in the blood of the newborn infants.

It is of practical interest that no significant differences in hypoxanthine concentrations were found when samples were obtained simultaneously from an umbilical artery and an umbilical vein, as venous blood samples are sometimes easier to obtain in clinical work.

The clinical value of the hypoxanthine concentration as an indication of perinatal hypoxia, as compared with the blood lactate level, base deficit, and $\mathrm{pH}$, will be discussed in a separate paper (26).

\section{REFERENCES AND NOTES}

1. Berg, D., and Dörrler, J.: Das Verhalten des Säure-Basen Haushalts am ersten Lebenstage unter besonderer Berücksichtigung der ersten Lebensminuten. Geburtsh. Frauenheilk., 29: 980 (1969).

2. Beutnagel, H., Gauch, D., and Fabel, H.: Blutgase und Säuren-Basen Haushalt von normalen Neugeborenen am ersten Lebenstag. Z. Geburtsh. Gynaekol., 175: 1 (1971).

3. Bland, R. D., Clarke, T. L., and Harden, L. B.: Rapid infusion of sodium bicarbonate and albumin into high-risk premature infants soon after birth: A controlled, prospective trial. Am. J. Obstet. Gynecol., 124: 263 (1976).

4. Bratteby, L. -E., and Swanström, S.: Arterial lactate and pyruvate concentration in the normal and asphyxiated newborn infant. In: Bossart, H., and Perret, C.: Lactate in acute conditions. pp 56-68. (International Symposium on Lactate in Acute Conditions, Basel 1978. S. Karger, Basel, 1979).

5. Celander, O.: Studies of the perinatal circulation. In: Cassels, D. E.: The heart and circulation in the newborn infant. pp. 98-110. (Grune and Stratton Inc., New York, 1966.)

6. Celander, O., and Mårlid, K.: Reactive hyperaemia in the foot and calf of the newborn infant. Acta Paediatr., 51: 544 (1962).

7. Engström, L., Karlberg, P., Rooth, G., and Tunell, R.: The onset of respiration. A study of respiration and changes in blood gases and acid base balance. pp. 1-48. (Association for the aid of Crippled Children, New York, 1966.)

8. Gårdmark, S., Jacobson, L., and Rooth, G.: Fetal and maternal acid-base balance and glucose metabolism in breech presentation. In: Gärdmark, S.: Studies on acid-base balance, carbohydrate and lipid metabolism in human fetal and maternal blood in clinical and experimental conditions during labour. pp. 12I123. (Studentlitteratur, Lund, 1974.)

9. Kaneoka, T., Aso, M., Ozono, H., and Shirakawa, K.: Materno-fetal blood biochemical profiling: Part III: Clinical significance of neonatal 15-minute blood biochemical profiling. Acta Neonatol. Jap. 13: 383 (1977).

10. Koch, G., and Wendel, H.: Adjustment of arterial gases and acid base balance in the newborn infant during the first week of life. Biol. Neonate., 12: 136 (1968).
11. Lipp, A., Tuschmid, P., Silberschmid. M., and Duc, G.: Arterial cord blood hypoxanthine and intrauterine hypoxia. Abstr. No. 35. 5th European Congress of Perinatal Medicine. Uppsala. June 9-12. (Almqvist and Wiksell International. Stockholm, 1976.)

12. Maaser, Von M., Schramm, D., Scheidt, B., and Frenzel, I.: Metodischer Beitrag zur Bestimmung von Hypoxanthin in Serum als Hypoxieparameter bei Neugeborenen. Kinderärtzl. Praxis, 8: 408 (1979).

13. Manzke, H., Dörner, K., and Grunitz, J.: Urinary hypoxanthine and uric acid excretion in newborn infants with perinatal complications. Acta Paediatr. Scand., 66: 713 (1977).

14. Manzke, H., Dörner, K., Grunitz, J., Anger, H., und Wensky, H.: Erhöhte Hypoxanthin-Kreatinin-und Alpha ${ }_{1}$-fetoprotein Ausscheidung im Urin von Neugeborenen mit Geburtskomplikationen. Monatsschr. Kinderheil., 124: 492 (1976).

15. Modanlou, H., Yeh, S., Hon, E. H., Forsythe, A.: Fetal and neonatal biochemistry and Apgar scores. Am. J. Obstet. Gynecol., 11: 942 (1973).

16. Oliver, T. K., Jr., Demis, J. A., and Bates, G. D.: Serial blood gas tensions and acid base balance during the first hour of life in human infants. Acta Paediatr. Scand., 50: 346 (1961).

17. Rooth, G.: Different methods for evaluation of hypoxia. In: Keller, P. J.: Contributions to gynecology and obstetrics. pp. 63-68. (S. Karger, Basel, 1977.)

18. Saugstad, O. D.: The determination of hypoxanthine and xanthine with a $\mathrm{PO}_{2}$ electrode. Pediatr. Res., 9: 575 (1975).

19. Saugstad, O. D.: Hypoxanthine as a measurement of hypoxia. Pediatr. Res., 9: $158(1975)$.

20. Saugstad, O. D., Bo, G., Ostrem, T., and Aasen, O. A.: Hypoxanthine levels of plasma during hypoxemia in dogs. Eur. Surg. Res., 9: 23 (1977).

21. Saugstad, O. D., Kroese, A., Myhre, H. D., and Andersen, R.: Alteration of plasma hypoxanthine concentration during ischemia in the forelimb of the pig. Scand. J. Clin. Lab. Invest., 37: 517 (1977).

22. Saugstad, O. D., and Ostrem, T.: Hypoxanthine and urate level of plasma during and after hemorrhagic hypotension in dogs. Eur. Surg. Res., 9: 48 (1977).

23. Saugstad, O. D., and Schrader, H.: The determination of inosine and hypoxanthine in rat brain during normothermia and hypothermia. Acta Neurol. Scand., 57: 281 (1978).

24. Saugstad, O. D., Schrader, H., and Aasen, A. O.: Alteration of the hypoxanthine level in cerebrospinal fluid as an indicator of tissue hypoxia. Brain Res., 112: 188 (1976).

25. Scholander, P. F.: Experimental studies on asphyxia in animals. In: Oxygen Supply to the Foetus. pp. 267-274 (Blackwell Scientific Publications, Oxford, 1960).

26. Swanström, S., and Bratteby, L. -E.: Hypoxanthine as a test of perinatal hypoxia as compared to lactate, base deficit and pH. Pediatr. Res., I6: 156 (1982).

27. Thalme, B., Belfrage, P., and Raabe, N.: Lumbar epidural anaesthesia in labour. I. Acid base balance and clinical condition of the mother, fetus and newborn child. Acta Obstet. Gynecol. Scand., 53: 27 (1974).

28. Tunell, R., Copher, D., and Persson, B.: The pulmonary gas exchange and blood gas changes in connection to birth. In: Stetson, J. B., and Swyer, P. R.: Neonatal intensive care. pp. 89-106. (Warren H. Green Inc., St. Louis, 1976.)

29. The parents were thoroughly informed about this investigation on the infants and gave their full consent to participation. The study was approved by the Ethical Committee of the Faculty of Medicine of Uppsala University.

30. The authors thank the staff of the Department of Obstetrics and Gynecology of the University Hospital of Uppsala for their support and Professor Gösta Rooth for reviewing the manuscript.

31. This research was supported by grants from the Bank of Sweden Tercentenary Foundation.

32. Requests for reprints should be addressed to: Dr. Lars-Eric Bratteby, Unit of Pediatric Physiology, University Hospital, S-750 14 Uppsala, Sweden.

33. Received for publication April 13, 1981

34. Accepted for publication July 10, 1981 